\title{
INTERSEXUALIDADE NUMA POPULAÇÃO DO CAMARÃO ESCAVADOR UPOGEBIA OMISSA GOMES CORRÊA, 1968 (DECAPODA: UPOGEBIIDAE) DO NORDESTE DO BRASIL
}

\author{
Dias, F. ${ }^{1, *} \&$ Almeida, A.O. ${ }^{1}$ \\ ${ }^{1}$ Universidade Federal de Pernambuco (UFPE), Campus Recife, Laboratório de Biologia de Crustáceos. \\ *Autor correspondente: silvafernandadias7@gmail.com
}

Upogebia omissa é um camarão escavador que constrói galerias no sedimento marinho e estuarino ao longo do Atlântico Ocidental desde a Flórida até o Brasil. Na infraordem Gebiidea, as aberturas genitais (gonóporos) são localizadas nas coxas do terceiro e quinto par de pereiópodos (P3 e P5) de fêmeas e machos, respectivamente. No entanto, alguns registros apontam a ocorrência de indivíduos intersexuados em $U$. omissa, ou seja, com gonóporos dos dois sexos simultaneamente, dificultando, o reconhecimento do sexo destes indivíduos. Porém, até o momento, nenhum estudo investigou com maiores detalhes esse fenômeno. Este trabalho descreve a frequência e morfologia externa de indivíduos intersexuados em uma população de U. omissa na Baía de Suape, Cabo de Santo Agostinho, Pernambuco. A amostragem foi realizada mensalmente entre Agosto de 2017 a Abril de 2018 no substrato lamoso da zona entremarés. Os camarões foram capturados manualmente sob rochas durante 1h30min de esforço. A ocorrência e o grau de desenvolvimento dos gonóporos foram analisados visando à identificação do sexo dos indivíduos. O comprimento da carapaça (CC) foi medido em todos os camarões. Dos 150 camarões coletados (CC 1,52-9,94 mm), 65 eram intersexuados, isto é, com gonóporos femininos e masculinos (CC 3,61-9,01 mm), 79 tinham apenas gonóporos femininos (CC 3,47-9,94 mm) (fêmeas) e em seis não foram observados gonóporos (CC 1,52-2,68 mm). Os intersexuados (CC $6.18 \pm 1.34 \mathrm{~mm}$ ) foram significativamente menores que os exemplares que apresentam apenas gonóporos femininos (CC $7.06 \pm 1.47$ $\mathrm{mm})(\mathrm{U}=1692.5 ; \mathrm{p}<0,05)$. Os gonóporos do P3 dos intersexuados foram classificados em rudimentares e desenvolvidos, enquanto os do P5 foram classificados como desenvolvidos. Destes, 54 tinham gonóporos do P3 e P5 desenvolvidos, seis exibiam o par do P3 rudimentar e o par do P5 desenvolvido, dois tinham um gonóporo do par do P3 rudimentar e outro desenvolvido e o par do P5 desenvolvido e três tinham o par de gonóporos do P3 desenvolvido e exibiam apenas um gonóporo desenvolvido no P5. Dada à variedade de ocorrência e diferentes graus de desenvolvimento encontrados, conclui-se que a identificação do sexo dos intersexuados com base na análise dos gonóporos não é possível. A análise da morfologia interna será, portanto crucial para esclarecer se a intersexualidade de $U$. omissa se limita apenas à morfologia externa ou está relacionada a alguma forma de hermafroditismo.

Palavras-chave: fauna críptica, endofauna, morfologia, hermafroditismo. 